\title{
sciendo
}

DOI 10.2478/sbe-2020-0011

SBE no. 15(1) 2020

\section{THE IMPACT OF INTERGENERATIONAL MOBILITY ON MSA GROWTH IN THE UNITED STATES}

\author{
MAURO JOSEPH \\ University of Central Arkansas, USA
}

\begin{abstract}
:
This paper explores the relationship between economic growth and intergenerational mobility in the United States. Data from metropolitan statistical areas in the U.S. is used to examine how two measures of intergenerational mobility impact growth rates. More precisely, I examine how absolute income mobility and relative income mobility are related the growth rate of real gross metropolitan product (RGMP) from 2001 to 2011. I find that absolute mobility has a positive relationship with RGMP growth over the time period, and that relative mobility exhibits a negative relationship with RGMP. Results are found to be robust to two stage least squares estimation.
\end{abstract}

Key words: Intergenerational Mobility, Absolute Mobility, RGMP Growth

\section{Introduction}

The relationship between inequality and economic growth over time has been difficult to discern. Many studies have examined whether these variables exhibited any causal relationship (Banerjee \& Duflo, 2003; Barro, 2000; Deininger \& Squire, 1996). In large part, these studies lead to inconclusive findings. However, the majority of research has focused on the relationship between growth and specific types of inequality, namely income inequality as measured by the Gini coefficient or the theil index. The objective of this study is to expand upon this area of research by examining how intergenerational income mobility relates to economic growth. This study looks at the relationship between absolute upward mobility (AM) and relative mobility (RM), both developed by Chetty et al. (2014) and economic growth at the metropolitan statistical area (MSA) level in the United States.

A large area of research examines the relationship between inequality and economic growth. Barro (2000) and Deininger \& Squire (1996) both find an inconclusive relationship between the two. Banerjee \& Duflo (2003) find an inverted u-shaped relationship between net changes in inequality and growth rates. They also find that changes in inequality in any direction are associated with reduced growth in the next period. This ambiguous relationship between inequality and growth has carried over to a 
variety of measures of inequality, such as the Gini coefficient and intergenerational income mobility. These inconsistencies have been highlighted in the literature and can be attributed to a number of various reasons ranging from quality of data (Deininger \& Squire, 1998) to inconsistent measures of inequality (Knowles, 2005). Marrero \& Rodríguez (2013) claim that the lack of a well-defined relationship between inequality and growth is because income inequality is a composite measure of inequality of opportunity (negative relationship with growth) and inequality of effort (positive relationship with growth). The relationship between income inequality and growth than depends upon which component is larger.

All these studies examine inequality and growth by measuring income inequality, usually using the Gini coefficient or the Theil index. This has left a gap in the literature regarding the relationship between intergenerational income mobility and economic growth. In the context of economic growth, mobility can be thought of as how efficient an economy is at allocating agents of a specific generation based upon their own abilities and achievements, rather than the achievements of their family (Maoz \& Moav, 1999; Owen \& Weil, 1998). At present, only one other study has explored the empirical relationship between intergenerational mobility and growth. Bradbury \& Triest (2016) examine the impact that mobility has on income growth in the U.S. at the commuting zone level. They find that higher levels of mobility do cause higher levels of income growth at a very local level.

While there has been little empirical work done studying the link between economic growth and intergenerational mobility, it has been the focus of theoretical studies. Galor \& Tsiddon (1997) find that during periods of technological invention, economies that experience increased mobility generate more technological progress and economic growth. Breen (1997) finds an inconclusive relationship between economic growth and social mobility. Owen \& Weil (1998) and Maoz \& Moav (1999) find the relationship between mobility and growth is one of mutual causation. More precisely, mobility tends to promote growth through a better allocation of education and human capital to the most able individuals. Growth influences mobility by altering incentives to gain education.

A shortcoming in this line of literature is the absence of substantial empirical evidence on the relationship between intergenerational mobility and economic growth, with the notable exception of Bradbury \& Triest (2016). Much of this stems from the absence of reliable estimates. Many studies typically measure intergenerational mobility empirically by calculating the intergenerational income elasticity (IGE) (Solon, 1992), which relies on measurements of permanent income. As such, data that spans decades is necessary. Also, the presence of life-cycle bias has proven some estimates over the past few decades to be biased (Grawe, 2006; Nybom \& Stuhler, 2016b). Chen et al. (2017) also finds that the ages which minimize life-cycle bias varies across country, making international comparisons of mobility estimates questionable. Finally, given that there exists a great deal of variation in income inequality, comparing intergenerational mobility across countries can lead to misleading results (Chetty et al., 2014; Corak, 2013). Taking all these hurdles into account, it is difficult to compile a dataset with the necessary number of observations 
needed to reach any meaningful conclusion regarding the relationship between the IGE and economic growth.

However, there are other measures of mobility, besides the IGE, that examine the relationship between a parent's rank in the income distribution and their child's rank, as well as the probability of transitioning to different percentiles of the distribution (Bhattacharya \& Mazumder, 2011; Corak, Lindquist, \& Mazumder, 2014; Dahl \& DeLeire, 2008). These estimates have been shown to exhibit minimal life-cycle bias compared to other mobility measures (Nybom \& Stuhler, 2016a). These findings, along with recent rankbased mobility estimates at the local level from across the U.S. from Chetty et al. (2014), allow for the construction of a dataset of necessary size to perform meaningful analysis. More precisely, in order to measure intergenerational income mobility, I adopt two measures developed by Chetty et al. (2014); AM and RM. AM measures the mean income distribution rank of children whose parents are at the 25th percentile of the national income distribution. AM then captures how high up in the national income distribution children from each area can reach. While the exact determinants of AM are unknown, it has been shown to be related with an area's level of income inequality, social capital, segregation and school quality (Chetty et al., 2014). RM on the other hand, measures the rank-rank correlation of a parent's rank in the income distribution with their child's rank in their income distribution. As such, RM is more closely related to mobility measures like the IGE and captures both upward and downward mobility across generations.

My study is closest in nature to Bradbury \& Triest (2016). They also utilize AM and RM to assess income growth and finds that areas with higher rates of AM and lower levels of RM leads to more growth at the commuting zone level. My study differs from theirs in several ways. First, there is a difference in the levels of geographic aggregation. Bradbury \& Triest (2016) conduct their analysis at the commuting zone level, which is a very local level. In this study, I use MSAs, which are larger geographically and examine primarily urban areas. This will allow me to examine if similar results are found at higher levels geographic aggregation of different compositions. This may have significant implications for economic policy, which is enacted at various levels. Another notable difference is the way economic growth is measured. Finally, the instruments used in the two-stage least squares (2SLS) analysis differ. In this study, I find that AM has a positive effect and RM has a negative effect on the growth rate of real gross metropolitan product (RGMP) from 2001 to 2011. Also, the impact that RM has on growth is weaker than that which is observed between AM and the growth rate. Similar results are found when using instrumental variables to control for model endogeneity.

This paper will proceed in the following manner. In Section 2, the dataset and model methodology are discussed. In Section 3, the empirical results are presented. Finally, Section 4 summarizes my findings, methods and discusses the implications of my results.

\section{Data \& Methodology}

In this section an overview of the all the variables used in the regression analysis is provided, as well as a description of the framework and methods used. The layout of this 
section will proceed in the following manner. First, a detailed explanation of the dataset used for the analysis is provided, as well as how the variables were created and selected. Following this, a thorough explanation of the empirical methodology used in the analysis is given.

Data

A self-compiled dataset is used to investigate the relationship between intergenerational mobility and economic growth at the MSA level. Economic growth is measured using the compound annual growth rate of RGMP of each MSA between 2001 and 2011, which is obtained from the Bureau of Economic Analysis (BEA). As mentioned previously, intergenerational mobility is measured using AM and RM. It is important to note that higher levels of AM signal higher levels of intergenerational mobility. However, higher levels of RM reflect a greater correlation between a parent's income rank and their child's rank and signal lower levels of intergenerational mobility. As such, a negative coefficient should be found for RM in the analysis.

In order to determine the other economically important variables that should be included in the growth regression, I turn to the literature pertaining to regional economic growth in the U.S. Crain and Lee (1999) conducts a sensitivity analysis regarding important variables to be included when estimating economic growth at the state level in the U.S. They find that the two most important variables to be included in any core set of regressors are the share of the population between the ages of 18 and 64 and the share of the population with a bachelor's degree or better. Mills and Lubuele (1995) estimates metropolitan area growth rates using 1970, 1980 and 1990 census data. They argue two of the most important variables in MSA growth rate regressions are population size and employment. Following Crain and Lee (1999), I measure the education level of the labor force of each MSA by measuring the percent of individuals in each MSA that have obtained a bachelor's degree or higher. This is computed from a five-year estimate (20072011) from the American Community Survey (ACS) conducted by the U.S. Census Bureau. The change in each MSA's population is measured using data from the 2000 and 2010 United States' Censuses to control for changes in population. I also measure the average percentage change in the monthly unemployment rate (UR) for each MSA from 2001 to 2011 with unemployment data from the Bureau of Labor Statistics (BLS) to account for employment in each MSA. Following Acs et al. (2002), I use the average amount of annual utility patents in each MSA from 2001 to 2011, according to the U.S. Patent Office, to control for differences in regional technology. To control for the role that government might play in the education of the workforce I use the average amount of education spending done in the state that the respective MSA resides in from 2000 to 2011. It is computed as the average annual real increase in education spending, measured as a percentage change and is obtained from BEA reports on annual state finances. The last variable of interest in my model is the percentage change in the house price index (HPI) from 2001 to 2011 at the MSA level. The data is obtained from the Federal Housing Finance Agency, following Miller et al. (2011). The final dataset is comprised of a sample of 297 observations. Since data is collected from a variety of government agencies, one 
drawback is that not every agency supplies data for each MSA in the United States. For example, the data used for unemployment rates is obtained from the BLS, and some MSAs are not reported because they are covered under "Core Based Statistical Areas" (CBSA). This leads to missing data for certain variables and some MSAs must be eliminated to make sure the dataset is as complete as possible. There was no systematic exclusion of these observations.

Table 1 presents summarizing statistics for the key variables in the dataset. Regional dummy variables for four major countrywide divisions (Northeast, Midwest, South and West) are created to control for regional fixed effects. MSAs are assigned into regions based upon their state and current U.S. Census delineations.

Table 1: Summary Statistics

\begin{tabular}{lrrrr} 
Variable & Mean & Standard Deviation & Min & Max \\
\hline RGMP Growth 2001-2011 & 1.52 & 1.32 & -1.70 & 8.30 \\
AM & 41.32 & 3.64 & 34.38 & 52.78 \\
RM & 33.18 & 3.64 & 18.00 & 43.00 \\
Average Change in Unemployment Rate (\%) & 0.80 & 0.28 & 2.51 & 0.17 \\
Population w/ Bachelor's Degree or Higher (\%) & 0.06 & 10.01 & 9.80 & 63.00 \\
Population Growth (\%) & 11.86 & 9.97 & -11.10 & 52.90 \\
Average Number of Utility Patents (hundreds) & 1.95 & 6.46 & 0.01 & 76.13 \\
Change in Education Spending (\%) & 2.52 & 1.14 & 0.15 & 4.99 \\
Change in HPI (\%) & 26.60 & 18.97 & -26.32 & 99.41 \\
\hline
\end{tabular}

\section{Empirical Framework}

In order to estimate the impact of absolute and relative mobility on RGMP growth the following equation will be estimated:

$$
\text { RGMPgr }=\beta_{0}+\beta_{1} \text { Mobility Measure }+\beta X
$$

Where the measure of mobility is either absolute mobility or relative mobility and $X$ contains the controls discussed in the previous section. The data observations vary across geographic locations of the U.S. and because of the vast differences that can be seen across the country it is important to control for regional effects in the growth regression. As such, the above equation is also estimated using regional fixed effects.

\section{Endogeneity}

The last major obstacle concerning the validity of my results is dealing with the likelihood that the AM and RM variables are endogenous. In order to rectify the potential endogeneity, I utilize instrumental variables and implement 2SLS estimation. This study will utilize two instruments to conduct 2SLS. The first instrument used is the rate of religious adherence per 1000 in the year 2000, taken from the Association of Religion Data 
Archives. This measure covers all denominations and is calculated as an average of all the counties within each MSA. In regard to the relevance of the rate of adherence as a suitable IV for AM, Chetty et al. (2014) find that areas that exhibit higher levels of AM and RM also have higher rates of religious adherence. Some further justification for this relationship is that it serves as a proxy of neighborhood structure and potential social networks. To tie this in to MSAs, the more religious adherents in an MSA the greater the number of religious institutions there are (churches, synagogues, etc.) These institutions provide a number of ways for children to learn and develop, plus these institutions will arise regardless of an area's income. At a place of worship for example, children may have to do extra reading, they have an opportunity to play musical instruments, participate in plays and so on. Furthermore, due to the close-knit nature of many of these congregations, many children have guidance from adults beyond their parents. These extra potential mentors and invested observers may help keep children in school, out of trouble and potentially even help them with job connections. This extra nourishing can help poor people have a means to develop skills, which in turn allows them to rise up the income ladder. It is also important to note that this variable simply captures the number of people who voluntarily adhere to any religion, not just a specific sect. As far as its validity as an instrument, it seems unlikely that the proportion of the population that adheres to religion would have an impact on the growth rate of an MSA, especially since it is not measuring any specific religion or sect but rather the fraction of people who identity as following a general religion. However, I examine this instrument's validity using Sargan's test for overidentifying restrictions in the analysis.

The second instrument used relies upon geographical indicators, which have been shown to serve as reliable instruments (Emran \& Hou, 2013; Frankel \& Romer, 1999). The construction of this variable rests upon the geographical variation of AM and RM in the U.S. While there is variation within each state, at the regional level there are some trends exhibited by both AM and RM. First, the southeast of the country is among the least mobile. The most mobile is the northern Midwest states. The northeast and the southwest are ranked in the middle (Chetty et al., 2014). An instrument for these measures of mobility can then be constructed using their geographical location within the country - more precisely the longitude and latitude of the principal city in each MSA. Latitude increases in value as one moves away from the equator. Longitude on the other hand increases in value as one moves further west. I construct a variable that is equal to the sum of each MSA's longitude and latitude. This sum will be smallest in the southeast and largest in the northwest. The northeast and the southwest will be in the middle. This relationship is similar to that of AM and RM and is unrelated to the economic growth rates of these MSA's.

\section{Results}

I first estimate the model using OLS to obtain estimates with and without regional fixed effects. The results are provided in Table 2. Columns (1) and (2) give the results for the model without regional fixed effects for AM and RM. Columns (3) and (4) provide the results for $A M$ and $\mathrm{RM}$ when the model is estimated with regional fixed effects. It can be 
observed that in all columns, the variable capturing intergenerational mobility is highly significant. When AM is used, it is found to be positive and significant at the $1 \%$ level. A positive sign on AM indicates that higher rates of AM lead to higher rates of growth. More precisely, an increase in the expected rank of a child born to parents in the 25th percentile of the income distribution of 10 percentiles will increase the expected growth rate by $0.90 \%$. This would mean that an MSA that growths at the average rate of $1.52 \%$ over the sample period would instead grow at about $2.4 \%$ if their level of AM was 40 instead of 30 . The magnitude of AM's effect on growth is observed to be higher when accounting for regional fixed effects. In this case, an MSA that growths at the average rate of $1.52 \%$ over the sample period would instead grow at about $2.8 \%$. RM is found to be negative and significant at the $5 \%$ level and $1 \%$ level for the model with and without fixed effects. More precisely, when accounting for regional fixed effects, a correlation between parent-child income ranks of 40 instead of 30 would grow $0.45 \%$ lower. As was the case with AM, the magnitude of RM increases after accounting for fixed effects $(-0.04$ versus -0.03$)$.

Table 2: OLS Regression Results

\begin{tabular}{|c|c|c|c|c|}
\hline & \multicolumn{4}{|c|}{ Dependent variable: } \\
\hline & \multicolumn{4}{|c|}{ RGMP Growth 2001-2011 } \\
\hline & $(1)$ & $(2)$ & (3) & $(4)$ \\
\hline \multirow[t]{2}{*}{ Absolute Mobility } & $0.09^{* * *}$ & & $0.13^{* * *}$ & \\
\hline & $(0.02)$ & & $(0.02)$ & \\
\hline \multirow[t]{2}{*}{ Relative Mobility } & & $-0.03^{* *}$ & & $-0.04^{\star \star *}$ \\
\hline & & $(0.01)$ & & $(0.02)$ \\
\hline \multirow[t]{2}{*}{ Average Change in Unemployment Rate (\%) } & $-0.39^{*}$ & $-0.48^{* *}$ & $-0.36^{*}$ & $-0.48^{* *}$ \\
\hline & $(0.22)$ & $(0.23)$ & $(0.22)$ & $(0.23)$ \\
\hline \multirow[t]{2}{*}{ Population w/ Bachelor's Degree or Higher (\%) } & $0.01^{* *}$ & $0.02^{* * *}$ & $0.02^{* \star *}$ & $0.02^{* \star \star}$ \\
\hline & $(0.01)$ & $(0.01)$ & $(0.01)$ & $(0.01)$ \\
\hline \multirow[t]{2}{*}{ Population Growth (\%) } & $0.05^{* * *}$ & $0.05^{* \star *}$ & $0.04^{* * *}$ & $0.04^{* * *}$ \\
\hline & $(0.01)$ & $(0.01)$ & $(0.01)$ & $(0.01)$ \\
\hline \multirow[t]{2}{*}{ Average Number of Utility Patents (hundreds) } & 0.01 & 0.004 & 0.005 & 0.003 \\
\hline & $(0.01)$ & $(0.01)$ & $(0.01)$ & $(0.01)$ \\
\hline \multirow[t]{2}{*}{ Change in Education Spending (\%) } & $0.17^{\star \star *}$ & $0.20^{* * *}$ & $0.13^{*}$ & $0.20^{* * *}$ \\
\hline & $(0.06)$ & $(0.06)$ & $(0.07)$ & $(0.07)$ \\
\hline \multirow[t]{2}{*}{ Change in HPI (\%) } & $0.01^{* *}$ & $0.01^{* * *}$ & $0.01^{* * *}$ & $0.01^{* * *}$ \\
\hline & $(0.003)$ & $(0.004)$ & $(0.003)$ & $(0.004)$ \\
\hline \multirow[t]{2}{*}{ Northeast } & & & $-1.05^{\star \star \star}$ & $-0.66^{* *}$ \\
\hline & & & $(0.26)$ & $(0.26)$ \\
\hline \multirow[t]{2}{*}{ Midwest } & & & $-0.62^{* * *}$ & -0.20 \\
\hline & & & $(0.20)$ & $(0.20)$ \\
\hline \multirow[t]{2}{*}{ West } & & & $-0.44^{* *}$ & -0.31 \\
\hline & & & $(0.19)$ & $(0.23)$ \\
\hline \multirow[t]{2}{*}{ Constant } & $-3.47^{\star \star \star}$ & $1.07^{* *}$ & $-4.71^{* \star *}$ & $1.67^{* *}$ \\
\hline & $(0.76)$ & $(0.54)$ & $(0.79)$ & $(0.75)$ \\
\hline Observations & 297 & 297 & 297 & 297 \\
\hline$R^{2}$ & 0.36 & 0.32 & 0.41 & 0.34 \\
\hline
\end{tabular}

Significance Codes: $10 \%^{*}, 5 \%{ }^{* *}, 1 \%$ *** 
Comparing the impact that the two measures of mobility have on growth reveals two important finding. First, both are found to be significantly different from zero at the $1 \%$ level, after controlling for fixed effects. Second, and more importantly, the magnitude of these effects is very different. After taking into account the differing signs, the impact of AM is greater than that of RM. This is similar to results found by Bradbury and Triest (2016), and suggests that AM plays a greater role in the growth process than RM. In regard to the other covariates, I find that educational attainment, population change and changes in the $\mathrm{HPI}$ are significant at the $1 \%$ level after accounting for regional fixed effects. The coefficients capturing unemployed and education spending are at least significant at the $10 \%$ level for AM and RM. All of the coefficients on these variables have the appropriate sign.

The results obtained from 2SLS for the model with and without regional fixed effects when using AM as the main measure of mobility are presented for the various sets of instruments in Table 3 . Output in this table is given by the set of instruments used. In columns (1) and (4), only religious adherents per 1000 people is used as an instrument. In columns (2) and (5) the geography-based instrument is used. Finally, in columns (3) and (6), I report results when using religious adherents and the geography-based variable. It can be seen that the coefficient for AM varies from 0.17 to 0.26 depending upon the set of instruments used and whether the fixed effects are included. However, in all cases, these coefficients are positive and significant at the $1 \%$ level, signaling that higher levels of AM contribute to higher levels of growth. Examining the results obtained from using the full set of instruments, I find that the direction and significance of the exogenous regressors are similar to those found under OLS, with some exceptions.

Table 3: 2SLS Regression Results using Absolute Mobility

\begin{tabular}{|c|c|c|c|c|c|c|}
\hline & \multicolumn{6}{|c|}{ RGMP Growth 2001-2011 } \\
\hline & $(1)$ & $(2)$ & (3) & (4) & $(5)$ & (6) \\
\hline \multirow[t]{2}{*}{ Absolute Mobility } & $0.18^{* * *}$ & $0.21^{* * *}$ & $0.19^{* \star *}$ & $0.17^{* * *}$ & $0.26^{* * *}$ & $0.19^{* \star *}$ \\
\hline & $(0.05)$ & $(0.06)$ & $(0.04)$ & $(0.04)$ & $(0.06)$ & $(0.04)$ \\
\hline \multirow[t]{2}{*}{ Average Change in Unemployment Rate (\%) } & -0.32 & -0.30 & -0.31 & -0.35 & -0.31 & -0.34 \\
\hline & $(0.24)$ & $(0.25)$ & $(0.24)$ & $(0.22)$ & $(0.24)$ & $(0.22)$ \\
\hline \multirow[t]{2}{*}{ Population w/ Bachelor's Degree or Higher (\%) } & 0.01 & 0.01 & 0.01 & $0.02^{* * *}$ & $0.02^{* *}$ & $0.02^{* * *}$ \\
\hline & $(0.01)$ & $(0.01)$ & $(0.01)$ & $(0.01)$ & $(0.01)$ & $(0.01)$ \\
\hline \multirow[t]{2}{*}{ Population Growth (\%) } & $0.05^{* * *}$ & $0.05^{* * *}$ & $0.05^{* * \star}$ & $0.04^{* * \star}$ & $0.04^{* \star *}$ & $0.04^{* * *}$ \\
\hline & $(0.01)$ & $(0.01)$ & $(0.01)$ & $(0.01)$ & $(0.01)$ & $(0.01)$ \\
\hline \multirow[t]{2}{*}{ Average Number of Utility Patents (hundreds) } & 0.005 & 0.004 & 0.004 & 0.005 & 0.004 & 0.005 \\
\hline & $(0.01)$ & $(0.01)$ & $(0.01)$ & $(0.01)$ & $(0.01)$ & $(0.01)$ \\
\hline \multirow[t]{2}{*}{ Change in Education Spending (\%) } & $0.16^{\star * \star}$ & $0.16^{\star *}$ & $0.16^{* \star \star}$ & 0.10 & 0.03 & 0.08 \\
\hline & $(0.06)$ & $(0.06)$ & $(0.06)$ & $(0.07)$ & $(0.09)$ & $(0.07)$ \\
\hline \multirow[t]{2}{*}{ Change in HPI (\%) } & 0.01 & 0.005 & 0.01 & $0.01^{* *}$ & $0.01^{*}$ & $0.01^{* *}$ \\
\hline & $(0.004)$ & $(0.004)$ & $(0.004)$ & $(0.003)$ & $(0.004)$ & $(0.004)$ \\
\hline \multirow[t]{2}{*}{ Northeast } & & & & $-1.18^{* \star *}$ & $-1.50^{* * *}$ & $-1.27^{* \star *}$ \\
\hline & & & & $(0.29)$ & $(0.34)$ & $(0.28)$ \\
\hline \multirow[t]{2}{*}{ Midwest } & & & & $-0.77^{* * *}$ & $-1.15^{\star \star *}$ & $-0.87^{* * *}$ \\
\hline & & & & $(0.25)$ & $(0.33)$ & $(0.24)$ \\
\hline West & & & & $-0.60^{\star *}$ & $-0.99^{* * *}$ & $-0.70^{* * *}$ \\
\hline
\end{tabular}




\section{Studies in Business and Economics no. 15(1)/2020}

\begin{tabular}{lcccccc} 
Constant & & & & $(0.24)$ & $(0.32)$ & $(0.23)$ \\
& $-7.21^{+* *+}$ & $-8.25^{*+*}$ & $-7.66^{*+*}$ & $-6.07^{+*+*}$ & $-9.35^{+*+}$ & $-6.92^{+*+*}$ \\
& $(2.02)$ & $(2.38)$ & $(1.51)$ & $(1.46)$ & $(2.28)$ & $(1.35)$ \\
\hline Observations & 297 & 297 & 297 & 297 & 297 & 297 \\
$R^{2}$ & 0.30 & 0.26 & 0.28 & 0.40 & 0.32 & 0.39 \\
\hline Diagnostic Tests & & & & & & \\
Wu-Hausman & 4.52 & 5.44 & 12.59 & 1.26 & 5.60 & 4.37 \\
$p$-value & 0.03 & 0.02 & 0.001 & 0.26 & 0.02 & 0.04 \\
Sargan & & & 0.11 & & & 2.13 \\
$p$-value & & & 0.74 & & & 0.14 \\
\hline
\end{tabular}

Significance Codes: $10 \%{ }^{*}, 5 \%^{* *}, 1 \%{ }^{* * *}$

Table 3 also reports the Wu-Hausman test and the Sargan statistic (when available) for each set of instruments. When examining the results for columns (1), (2), (3), (5) and (6), the Wu-Hausman test reveals that endogeneity is a significant problem. As such, the coefficients obtained in Table 2 under OLS are inconsistent. In this case, the 2SLS coefficients should be used. However, these coefficients are positive and highly significant, lending support to mobility's impact on MSA growth. It is also important to observe that under 2SLS, AM's impact on MSA growth is greater in magnitude then under OLS. Finally, in order to test over-identifying restrictions, I employ the Sargan test, which is reported at the bottom of columns (3) and (6) in Table 3. In both cases, I fail to reject the null hypothesis and find the instruments used are valid. Taking these tests into account, the OLS results are inconsistent, however a valid set of instruments has been used and results found under 2SLS can be trusted and show the positive and significant impact of AM on MSA growth.

Table 4: 2SLS Regression Results using Relative Mobility

\begin{tabular}{|c|c|c|c|c|c|c|}
\hline & \multicolumn{6}{|c|}{ RGMP Growth 2001-2011 } \\
\hline & (1) & $(2)$ & (3) & (4) & (5) & (6) \\
\hline \multirow[t]{2}{*}{ Relative Mobility } & -0.002 & $-0.08^{\star \star \star}$ & $-0.08^{\star \star *}$ & $-0.10^{* *}$ & $-0.19^{* \star \star}$ & $-0.21^{* * *}$ \\
\hline & $(0.05)$ & $(0.02)$ & $(0.02)$ & $(0.04)$ & $(0.05)$ & $(0.05)$ \\
\hline \multirow[t]{2}{*}{ Average Change in Unemployment Rate (\%) } & $-0.46^{*}$ & $-0.51^{* *}$ & $-0.51^{* *}$ & $-0.56^{* *}$ & $-0.68^{* *}$ & $-0.72^{* *}$ \\
\hline & $(0.24)$ & $(0.24)$ & $(0.24)$ & $(0.24)$ & $(0.27)$ & $(0.28)$ \\
\hline \multirow[t]{2}{*}{ Population w/ Bachelor's Degree or Higher (\%) } & $0.02^{* *}$ & $0.02^{* \star *}$ & $0.02^{* \star *}$ & $0.02^{\star \star *}$ & $0.02^{* * *}$ & $0.02^{* * *}$ \\
\hline & $(0.01)$ & $(0.01)$ & $(0.01)$ & $(0.01)$ & $(0.01)$ & $(0.01)$ \\
\hline \multirow[t]{2}{*}{ Population Growth (\%) } & $0.06^{* \star}$ & $0.04^{* * *}$ & $0.04^{* * *}$ & $0.03^{* * *}$ & $0.02^{*}$ & 0.02 \\
\hline & $(0.01)$ & $(0.01)$ & $(0.01)$ & $(0.01)$ & $(0.01)$ & $(0.01)$ \\
\hline \multirow[t]{2}{*}{ Average Number of Utility Patents (hundreds) } & 0.01 & -0.004 & -0.005 & 0.0001 & -0.004 & -0.01 \\
\hline & $(0.01)$ & $(0.01)$ & $(0.01)$ & $(0.01)$ & $(0.01)$ & $(0.01)$ \\
\hline \multirow[t]{2}{*}{ Change in Education Spending (\%) } & $0.18^{* * *}$ & $0.21^{* \star *}$ & $0.22^{* * *}$ & $0.17^{* *}$ & 0.11 & 0.10 \\
\hline & $(0.06)$ & $(0.06)$ & $(0.06)$ & $(0.08)$ & $(0.09)$ & $(0.09)$ \\
\hline \multirow[t]{2}{*}{ Change in HPI (\%) } & $0.01^{* * *}$ & $0.01^{* * *}$ & $0.01^{* \star *}$ & $0.01^{* * *}$ & $0.01^{* * *}$ & $0.01^{* * *}$ \\
\hline & $(0.004)$ & $(0.004)$ & $(0.004)$ & $(0.004)$ & $(0.004)$ & $(0.004)$ \\
\hline \multirow[t]{2}{*}{ Northeast } & & & & $-0.72^{\star \star \star}$ & $-0.81^{* \star *}$ & $-0.84^{* \star *}$ \\
\hline & & & & $(0.27)$ & $(0.30)$ & $(0.31)$ \\
\hline & 135 - & & & & & \\
\hline
\end{tabular}




\begin{tabular}{|c|c|c|c|c|c|c|}
\hline \multirow[t]{2}{*}{ Midwest } & & & & -0.33 & & \\
\hline & & & & $(0.22)$ & $(0.25)$ & $(0.20)$ \\
\hline \multirow[t]{2}{*}{ West } & & & & $-0.83^{* *}$ & $-1.62^{\star \star \star}$ & $-1.83^{* * \star}$ \\
\hline & & & & $(0.41)$ & $(0.51)$ & $(0.50)$ \\
\hline \multirow[t]{2}{*}{ Constant } & 0.07 & $2.60^{\star \star *}$ & $2.76^{\star \star *}$ & $3.98^{\star *}$ & $7.45^{\star \star \star}$ & $8.40^{\star \star \star}$ \\
\hline & $(1.66)$ & $(0.80)$ & $(0.80)$ & (1.69) & $(2.10)$ & $(2.08)$ \\
\hline Observations & 297 & 297 & 297 & 297 & 297 & 297 \\
\hline$R^{2}$ & 0.31 & 0.29 & 0.29 & 0.31 & 0.26 & 0.28 \\
\hline \multicolumn{7}{|c|}{ Diagnostic Tests: } \\
\hline Wu-Hausman & 4.82 & 7.61 & 9.32 & 2.45 & 11.90 & 18.50 \\
\hline$p$-value & 0.03 & 0.01 & 0.002 & 0.12 & 0.001 & 0.003 \\
\hline Sargan & & & 13.20 & & & 2.23 \\
\hline$p$-value & & & 0.01 & & & 0.14 \\
\hline
\end{tabular}

Significance Codes: $10 \% *, 5 \% * *, 1 \%$ ***

Table 4 provides the results for the model when using RM as the measure of intergenerational mobility for the different sets of instruments. Output in this table is done in the same order as Table 3. RM is found to be at least significant at the $5 \%$ level under all instrument iterations for the model with and without fixed effects, with the exception of column (1). In all cases a negative sign is obtained for RM, as was the case under OLS. The magnitude of RM varies more dramatically than AM, ranging from near 0 to -0.21 . The signs on the other regressors are the same as under OLS, however the significance of these estimates has changed. The Wu-Hausman test suggests that endogeneity is a significant problem under all model specifications, with the exception of column (4). The inconsistency of the OLS estimators means the S2LS estimators must be relied upon. Still, they are found to be significantly negative, meaning that higher levels of relative mobility are associated with lower levels of MSA growth. They are also greater in magnitude than under OLS. The instruments are found to be valid when the full model with regional fixed is estimated. Finally, it should be noted that when comparing the two sets of results for AM and RM, results are stronger and more significant when mobility is measured in absolute terms.

\section{Life-Cycle Bias Concerns}

Along with the endogeneity concerns previously discussed, another issue that should be taken into account is the potential for any life-cycle bias in the measures of intergenerational mobility used, as this has been shown to be a growing concern in empirical mobility estimates (Chen et al., 2017; Grawe, 2006; Nybom \& Stuhler, 2016a). It is important to note that absolute and relative mobility at the MSA level is calculated using child incomes when they are about 30 years of age (Chetty et al., 2014). This suggests that there is potential for the permanent income of these "children" to change over time. Ideally, measures of permanent income should be constructed using a multiyear average at later points in life (Solon, 1992). However, due to the limited available data used to construct both absolute and relative mobility this is not possible. Instead, I turn to the literature for guidance on how susceptible measures of income mobility are to life cycle 
bias and how this might impact the model's findings. Nybom and Stuhler (2016b) use Swedish income data from 1960-2007 to estimate how life-cycle bias impacts intergenerational earnings elasticity. They find that intergenerational elasticity measures suffer from life-cycle bias when using short snapshots of income. These biases can be minimized by measuring income around midlife, although no ideal age is found. A similar result is found by Chen et al. (2017) using Canadian income data. They obtain an intergenerational earnings elasticity for Canada of around 0.32 , which is about 0.10 higher than previous estimates. About two-thirds of this discrepancy is attributed to life-cycle bias. They also find that the presence of life-cycle bias is more pronounced at the top end of the income distribution. Nilsen et al. (2012) reaches similar conclusions regarding previous estimates of intergenerational mobility in Norway, which have been overstated. They find that extending the father's earnings window from 5 to 25 years increases estimated elasticities twofold. Nybom and Stuhler (2016a) builds upon previous work to measure how different measures of intergenerational mobility are affected by life-cycle bias. Again, using income data from Sweden, they find that life-cycle bias is strongest in the intergenerational elasticity measure and smallest in rank-based measures. In particular, they find that rank correlation is notably stable when long-run benchmark income measures are compared with age-specific income measures from ages 30-50, lending support to the validity of findings by Chetty et al. (2014).

Taking these empirical studies into account I can hypothesize about the potential impact that life-cycle bias might have on my analysis. The main measures of intergenerational income mobility used are absolute mobility and relative mobility. The construction of absolute mobility is achieved by calculating the expected rank in the income distribution of a child born to a parent in the $25^{\text {th }}$ percentile of the national income distribution. Since AM is a rank-based measure of intergenerational mobility, it is less sensitive to life-cycle bias than other measures of mobility (Nybom \& Stuhler, 2016b). Also, this specific measure of mobility focuses on the upward movement of child whose parents are at the lower end of the income distribution. As previously stated, research has shown that life-cycle bias is much more pronounced at the top end of the income distribution. Like absolute mobility, relative mobility is also a rank-based measure that captures the correlation between parent and child income ranks. However, relative mobility examines these correlations from the bottom and the top of the income distribution. As such, relative mobility may be more susceptible to life-cycle bias than absolute mobility. In both cases, life-cycle bias may still be a concern, and could impact my findings. However, its effects have been minimized, especially in the case of absolute mobility.

The only other concern arising from the presence of life-cycle bias is whether its impact on rank-based mobility measures varies geographically across MSAs. While there is little guidance on this issue at the regional level in the U.S., Chen et al. (2017) does examine cross-country differences in life-cycle bias. They find that the age at which lifecycle bias is minimized varies from country to country making international comparisons of mobility estimates difficult. This coupled with the large geographic differences in mobility estimates found by Chetty et al. (2014), might suggest that life-cycle bias does vary across MSAs. Unfortunately, there is no empirical evidence thus far that supports or refutes this. As a consequence, its potential presence does weaken my findings. Briefly summarizing 
all these issues, it is possible that the presence of life-cycle bias might suggest that my findings of intergenerational mobility's impact on MSA growth are potentially overstated.

\section{Discussion}

The goal of this study was to evaluate the relationship between intergenerational mobility and economic growth using empirical data. In theory, economies which have higher rates of mobility will experience a more efficient sorting of talent in the economy because individuals are judged less on parental achievements and more on their own. In turn, this process of the highest ability agents rising to the top will increase economic growth in the society. This has been the finding of many theoretical studies, but there has been little empirical evidence of this. I use a cross-sectional dataset of MSAs in the U.S. and find that both absolute and relative mobility have a significant effect on the growth rate of RGMP of MSAs from 2001 to 2011. While the preliminary OLS results were found to suffer from endogeneity, my results are found to be significant under 2SLS when valid instruments are used.

These findings are in line with those obtained by Bradbury and Triest (2016). They also find a significant and positive relationship between intergenerational mobility and economic growth. However, they utilize different levels of aggregation and instruments to control for endogeneity. One of the main contributions of my study then is to offer confirmation of the impact of intergenerational mobility at higher levels of geographic aggregation and in more urban areas. Second, the validation of two sets of instruments that might enable better research between mobility and growth in the U.S. Also, in line with findings by Bradbury and Triest (2016), I find that AM has a greater impact on economic growth than RM.

There are a few possible explanations for why this may be the case. First, it may be that RM is more susceptible to life-cycle bias than AM. This may be because it captures both upwards and downwards mobility. As such, it is plausible that RM is as important to growth as AM, however accurate measurement is more difficult. Second, intergenerational mobility measured in absolute terms may simply be more instrumental in the growth process. Economic theory suggests that production inputs are paid their marginal products. As such, one can think of the income distribution in each generation as a pseudo ranking of talent, with higher ability agents at the top and lower ones at the bottom. Intergenerational mobility then measures the ability of an economy to allocate their labor resources upon their productivity and not that of past generations. In this sense, AM specifically captures direct movement in the income distribution from generation. It is possible then that AM better measures the reallocation of talent than other relative or elasticity-based mobility measures and is more influential to growth.

The findings of this study have important implications for research in the field and economic policy. First, this study empirically verifies that intergenerational mobility plays a role in economic growth. Second, in terms of economic policy, increasing intergenerational mobility is not simply about economic equality, but may have important implications for economic growth. Often intergenerational mobility is cast in the same scope as income inequality, and as such is often debated about in terms of "fairness". A key result of this 
study is that policies aimed at increasing mobility, while focusing on increasing equality and opportunity, may also lead to increased economic performance. Finally, it appears that the impact of mobility on growth is consistent at different levels of geographic aggregation.

While this study has provided some evidence of the positive impact that intergenerational mobility has on economic growth at the MSA level there are significant gaps in the research that should be pursued in the future. First, the precise channel through which AM and RM impact MSA growth is still unknown. As pointed out by Marrero and Rodríguez (2013), measures of income inequality are dominated by inequality of opportunity and inequality of effort. In the context of this study, higher levels of mobility may lead to higher levels of growth because there is greater access to opportunities in areas with more mobility. This may suggest that in MSAs with higher levels of mobility, human capital is accumulated by individuals with greater skills and talents, rather than by individuals of certain family backgrounds. This is echoed by Gaer et al. (2001), who find that inequality of opportunity reduces the role that talent plays and worsens intergenerational mobility.

As such, it is difficult to understand precisely how greater levels of AM and lower levels of RM lead to greater levels of economic growth. This implies that results found here, and similar ones found by Bradbury and Triest (2016) should be interpreted with caution. Future research should be devoted to several pursuits. First, measurements such as $\mathrm{AM}$ and RM should be estimated in other countries besides the U.S. This will allow researchers to examine the role that mobility plays in other countries. Second, the determinants of both AM and RM are still unknown. Chetty et al. (2014) find that these measures are correlated with a number of characteristics but there is little to no causal evidence of what influences AM or RM. Finally, a greater understanding of life-cycle bias in measures of intergenerational mobility is needed, along with more mobility estimates that are less sensitive to it. In closing, I have shown that AM and RM have a significant relationship with economic growth, which lends some evidence to theoretical studies examining the impact of intergenerational mobility on economic growth and provides verification of earlier empirical studies.

\section{References}

Acs, Z. J., Anselin, L., \& Varga, A. (2002). Patents and innovation count as measures of regional production of new knowledge. Research Policy, Vol. 31, no. 7, pp. 1069-1085.

Banerjee, A. V., \& Duflo, E. (2003). Inequality and Growth: What Can the Data Say? Journal of Economic Growth, Vol. 8, no 3, pp. 267-299. https://doi.org/10.1023/A:1026205114860

Barro, R. J. (2000). Inequality and Growth in a Panel of Countries. Journal of Economic Growth, Vol. 5, no. 1, pp. 5-32. https://doi.org/10.1023/A:1009850119329

Bhattacharya, D., \& Mazumder, B. (2011). A nonparametric analysis of black-white differences in intergenerational income mobility in the United States. Quantitative Economics, Vol. 2, no. 3, pp. 335-379. https://doi.org/10.3982/QE69

Bradbury, K., \& Triest, R. K. (2016). Inequality of Opportunity and Aggregate Economic Performance. RSF: The Russell Sage Foundation Journal of the Social Sciences, Vol. 2, no. 2, pp. 178201.

Breen, R. (1997). Inequality, economic growth and social mobility. The British Journal of Sociology, Vol. 48, no. 3, pp. 429-449. https://doi.org/10.2307/591139 
Chen, W.-H., Ostrovsky, Y., \& Piraino, P. (2017). Lifecycle variation, errors-in-variables bias and nonlinearities in intergenerational income transmission: New evidence from Canada. Labour Economics, Vol. 44, pp. 1-12. https://doi.org/10.1016/j.labeco.2016.09.008

Chetty, R., Hendren, N., Kline, P., \& Saez, E. (2014). Where is the land of Opportunity? The Geography of Intergenerational Mobility in the United States. The Quarterly Journal of Economics, Vol. 129, no. 4, pp. 1553-1623.

Corak, M. (2013). Income Inequality, Equality of Opportunity, and Intergenerational Mobility. Journal of Economic Perspectives, Vol. 27, no. 3, pp. 79-102. https://doi.org/10.1257/jep.27.3.79

Corak, M., Lindquist, M. J., \& Mazumder, B. (2014). A comparison of upward and downward intergenerational mobility in Canada, Sweden and the United States. Labour Economics, Vol. 30, pp. 185-200. https://doi.org/10.1016/j.labeco.2014.03.013

Crain, W. M., \& Lee, K. J. (1999). Economic Growth Regressions for the American States: A Sensitivity Analysis. Economic Inquiry, Vol. 37, no. 2, pp. 242-257. https://doi.org/10.1111/j.1465-7295.1999.tb01428.x

Dahl, M. W., \& DeLeire, T. (2008). The association between children's earnings and fathers' lifetime earnings: Estimates using administrative data. University of Wisconsin-Madison, Institute for Research on Poverty.

Deininger, K., \& Squire, L. (1996). A New Data Set Measuring Income Inequality. World Bank Economic Review, Vol. 10, no. 3, pp. 565-591. https://doi.org/10.1093/wber/10.3.565

Deininger, K., \& Squire, L. (1998). New ways of looking at old issues: inequality and growth. Journal of Development Economics, Vol. 57, no. 2, pp. 259-287. https://doi.org/10.1016/S03043878(98)00099-6

Emran, M. S., \& Hou, Z. (2013). Access to Markets and Rural Poverty: Evidence from Household Consumption in China. The Review of Economics and Statistics, Vol. 95, no. 2, pp. 682-697. https://doi.org/10.1162/REST_a_00354

Frankel, J. A., \& Romer, D. H. (1999). Does Trade Cause Growth? American Economic Review, Vol. 89, no. 3, pp. 379-399. https://doi.org/10.1257/aer.89.3.379

Gaer, D. V. D., Schokkaert, E., \& Martinez, M. (2001). Three Meanings of Intergenerational Mobility. Economica, Vol. 68, no. 272, pp. 519-538. https://doi.org/10.1111/1468-0335.d01-15

Galor, O., \& Tsiddon, D. (1997). Technological Progress, Mobility, and Economic Growth. The American Economic Review, Vol. 87, no. 3, pp. 363-382.

Grawe, N. D. (2006). Lifecycle bias in estimates of intergenerational earnings persistence. Labour Economics, Vol. 13, no. 5, pp. 551-570. https://doi.org/10.1016/j.labeco.2005.04.002

Knowles, S. (2005). Inequality and Economic Growth: The Empirical Relationship Reconsidered in the Light of Comparable Data. The Journal of Development Studies, Vol. 41, no. 1, pp. 135159. https://doi.org/10.1080/0022038042000276590

Maoz, Y. D., \& Moav, O. (1999). Intergenerational Mobility and the Process of Development. The Economic Journal, Vol. 109, no. 458, pp. 677-697. https://doi.org/10.1111/1468-0297.00468

Marrero, G. A., \& Rodríguez, J. G. (2013). Inequality of opportunity and growth. Journal of $\begin{array}{llll}\text { Development } \quad \text { Economics, } & \text { Vol. 104, } & \text { 122. }\end{array}$ https://doi.org/10.1016/j.jdeveco.2013.05.004

Miller, N., Peng, L., \& Sklarz, M. (2011). House Prices and Economic Growth. The Journal of Real Estate Finance and Economics, Vol. 42, no. 4, pp. 522-541. https://doi.org/10.1007/s11146009-9197-8

Mills, E. S., \& Lubuele, L. S. (1995). Projecting Growth of Metropolitan Areas. Journal of Urban Economics, Vol. 37, no. 3, pp. 344-360. https://doi.org/10.1006/juec.1995.1018

Nilsen, Ø. A., Vaage, K., Aakvik, A., \& Jacobsen, K. (2012). Intergenerational Earnings Mobility Revisited: Estimates Based on Lifetime Earnings. The Scandinavian Journal of Economics, Vol. 114, no 1, pp. 1-23. https://doi.org/10.1111/j.1467-9442.2011.01672.x 


\section{Studies in Business and Economics no. 15(1)/2020}

Nybom, M., \& Stuhler, J. (2016a). Biases in Standard Measures of Intergenerational Income Dependence. Journal of Human Resources, Vol. 52, no. 3, pp. 800-825. https://doi.org/10.3368/jhr.52.3.0715-7290R

Nybom, M., \& Stuhler, J. (2016b). Heterogeneous Income Profiles and Lifecycle Bias in Intergenerational Mobility Estimation. Journal of Human Resources, Vol. 51, no. 1, pp. 239268. https://doi.org/10.3368/jhr.51.1.239

Owen, A. L., \& Weil, D. N. (1998). Intergenerational earnings mobility, inequality and growth. Journal of Monetary Economics, Vol. 41, no. 1, pp. 71-104. https://doi.org/10.1016/S03043932(97)00067-6

Solon, G. (1992). Intergenerational Income Mobility in the United States. The American Economic Review, Vol. 82, no. 3, pp. 393-408. 